\begin{tabular}{cc|c}
\hline Tar. Bil. Der. & Tarım Bilimleri Dergisi & Journal of Agricultural Sciences \\
& $\begin{array}{c}\text { Dergi web sayfası: } \\
\text { www.agri.ankara.edu.tr/dergi }\end{array}$ & Journal homepage: \\
& www.agri.ankara.edu.tr/journal
\end{tabular}

\title{
Development of a Small-sized and Low-cost Attitude Measurement Unit for Agricultural Robot Application
}

\author{
Yufei LIU $^{\text {ac }}$, Noboru NOGUCHI ${ }^{\text {, }}$, Hiroshi OKAMOTO ${ }^{\text {b }}$, Kazunobu ISHII $^{\text {b }}$ \\ ${ }^{a_{Z}}$ Zhejiang University, College of Biosystems Engineering and Food Science, 866 Yuhangtang Road, Hangzhou, Zhejiang, CHINA

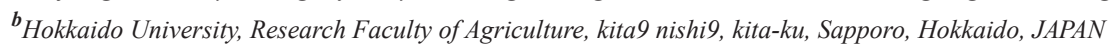 \\ ${ }^{c}$ Hokkaido University, Graduate School of Agriculture, kita9 nishi9, kita-ku, Sapporo, Hokkaido, JAPAN
}

\section{ARTICLE INFO}

Research Article DOI: 10.15832/ankutbd.446369

Corresponding Author: Noboru NOGUCHI, E-mail: noguchi@cen.agr.hokudai.ac.jp, Tel: +81 (011) 7063847

Received: 15 June 2016, Received in Revised Form: 07 September 2016, Accepted: 07 September 2016

\begin{abstract}
The objective of this study was to develop a small-sized and low-cost unit to provide attitude measurements for lightloaded, small-sized and cost effective agricultural robot application. The attitude measurement unit comprised an electronic control unit (ECU) and a gyroscope and an accelerometer within a small-sized and low-cost IMU. In order to avoid the measurement limitations of a single sensor, a self-adaptive complementary filter and a Kalman filter were discussed and compared for sensor fusion. By comparison, in respect of preventing angle drift and maintaining dynamic characteristics, the Kalman filter has the significant advantage, especially in dynamic motion. In the comparison with a highly precise aviation-level fiber optic gyroscope (FOG), the results showed that the static angle drift was restrained by Kalman filter which reached the performance of the FOG. And in the series of farm experiments, the dynamic characteristic of the developed attitude measurement unit is close to the FOG performance in the sub-degree level. This is an acceptable accuracy for light-loaded, small-sized and cost effective agricultural robot application such as agriculture drone, greenhouse robots, harvesting robot arm and so on.
\end{abstract}

Keywords: IMU sensor; Complementary filter; Kalman filter; Sensor fusion; Attitude estimation

\section{Tarımsal Robot Uygulamaları için Küçük Boyutlu ve Düşük Maliyetli Konum Ölçüm Ünitesinin Geliştirilmesi}

\section{ESER BILGISİ}

Araştırma Makalesi

Sorumlu Yazar: Noboru NOGUCHI, E-posta: noguchi@cen.agr.hokudai.ac.jp, Tel: +81 (011) 7063847

Geliş Tarihi: 15 Haziran 2016, Düzeltmelerin Gelişi: 07 Eylül 2016, Kabul: 07 Eylül 2016

\section{ÖZET}

$\mathrm{Bu}$ çalışmanın amacı; hafif, küçük boyutlu ve uygun maliyetli tarımsal robot uygulamaları için konum ölçümlerini sağlayan küçük boyutlu ve düşük maliyetli bir ünitenin geliştirilmesidir. Konum ölçüm ünitesi; bir elektronik kontrol ünitesi (ECU), bir jiroskop ile küçük boyutlu ve düşük maliyetli atalet ölçüm ünitesi (IMU) içeren bir ivmeölçerden 
oluşmaktadır. Tek bir sensörün ölçüm sınırlamalarından kaçınmak amacıyla, sensör birleştirmeleri için otomatik ayarlı bir tamamlayıcı filtre ve Kalman filtresi ele alınmış ve karşılaştırılmıştır. Karşılaştırmada, açı kaymasının önlenmesi ve dinamik özelliklerin muhafazası bakımından Kalman filtresinin, özellikle dinamik hareket nedeniyle önemli avantaja sahip olduğu ortaya çıkmıştır. Sonuçlar havacılıkta kullanılan yüksek hassasiyetli bir fiber optik jiroskop (FOG) ile karşılaştırıldığında, Kalman filtresi tarafından belirlenen statik açı kayması sonuçlarının FOG'un performansına yaklaşıldığını göstermiştir. Tarla denemelerinde, geliştirilen konum ölçüm ünitesinin dinamik karakteristiği FOG'un performansına yakın bulunmuştur. Bulunan bu sonuçlar; tarımsal amaçlı kullanılan insansız hava araçları (dronlar), sera robotları, hasat robot kolları gibi hafif, küçük boyutlu ve uygun maliyetli tarımsal robot uygulamaları için kabul edilebilir bir hassasiyettir.

Anahtar Kelimeler: IMU sensör; Tamamlayıcı filtre; Kalman filtre; Sensör birleştirme; Konum tahminleme

\section{Introduction}

The role of robotics in precision agriculture (PA) is becoming more and more important with the development of electronic technology. By combining with various advanced sensors, it has become possible for agricultural machines to do farming tasks autonomously. A global positioning system (GPS) has recently been used extensively in autonomous navigation for providing position information. For higher navigation accuracy, attitude sensors such as a geomagnetic direction sensor (GDS), FOG and an inertial measurement unit (IMU) can be utilized to correct the GPS position information. There have been a considerable number of studies on application of GPS with attitude sensors (Kise et al 2001; Noguchi et al 2001; Inoue et al 2009). Much progress has also been made in large-scale mechanization, which has advantages of high strength workload and labor cost reduction. However, now more attention is being given to small-sized smart agricultural machines (Robinson 2012). In order to keep the soil loose, there is a need to develop light-weight, small-sized, low-power and low-cost systems for agricultural robotic applications. Therefore, the development of a small-sized and low-cost attitude measurement system is necessary.

Two sensors, a gyroscope and an accelerometer, were used to measure the attitude of an agricultural robot. A gyroscope is an inertial sensor for measuring orientation based on the principles of angular momentum. However, because of noise jamming, temperature variation and unstable force moment, system drift error will occur and increase with time. Therefore, a gyroscope cannot be reliably used for a long time. Otherwise, an accelerometer is a device that measures proper acceleration. When the accelerometer is motionless, the attitude angles can be calculated on the basis of the acceleration of gravity component in every axis via trigonometric functions. However, an accelerometer cannot distinguish between the acceleration of gravity and external acceleration. Therefore, in the case of frequent variable accelerated motion and a bumpy outdoor field, the use of only an accelerometer is not appropriate for calculating attitude angle. Thus, the use of only a gyroscope or an accelerometer is not appropriate for a farming operation over a long period and in a complex environment.

The objective of this study was to develop a small-sized and low-cost unit including an ECU and an IMU to provide attitude measurement with acceptable accuracy for light-loaded, small-sized and low-priced agricultural robot application. Data processing used the sensor fusion principle including a self-adaptive complementary filter and a Kalman filter to integrate data from the gyroscope and accelerometer in the IMU.

\section{Material and Methods}

\subsection{Hardware platform}

For a small agricultural machine development, size and price are the two main parameters that must be 
considered in the design idea. In this study, a smallsized and low-cost IMU (S4E5A0A0A1, Seiko Epson) was used as the inertial sensor. This IMU with six degrees of freedom is compact $(24 \times 24 \times 10$ $\mathrm{mm}^{3}$ ) and only weighs 7 grams. It is composed of a triaxial micro-electro-mechanical system (MEMS) accelerometer, a triaxial quartz-MEMS (QMEMS) gyroscope and a temperature sensor. Outputs of the IMU include chip temperature, triaxial angular rates and linear accelerations in real time. The main performance and specifications of the IMU are shown in Table 1.

Table 1- Main performance and specifications of the IMU

\begin{tabular}{|c|c|c|}
\hline Parameters & Type & Unit \\
\hline \multicolumn{3}{|l|}{ Gyroscope } \\
\hline Dynamic range & \pm 300 & $\operatorname{deg} \mathrm{s}^{-1}$ \\
\hline Initial error & 0.5 & $\operatorname{deg} \mathrm{s}^{-1}$ \\
\hline In-run bias stability & 6 & $\operatorname{deg} h^{-1}$ \\
\hline Angular random walk & 0.2 & Deg $\sqrt{ } h^{-1}$ \\
\hline Noise density & 0.004 & $\operatorname{deg~s}{ }^{-1} \sqrt{ } \mathrm{Hz}^{-1}$ \\
\hline \multicolumn{3}{|l|}{ Accelerometer } \\
\hline Dynamic range & \pm 3 & G \\
\hline Initial error & 8 & $\mathrm{mG}$ \\
\hline In-run bias stability & 0.1 & $\mathrm{mG}$ \\
\hline Velocity random walk & 0.04 & $\mathrm{mG} \sec ^{-1} \sqrt{ } \mathrm{hr}^{-1}$ \\
\hline Noise density & 0.06 & $\mathrm{mG} \sqrt{ } \mathrm{Hz}^{-1}, \mathrm{rms}$ \\
\hline
\end{tabular}

An ECU (Due, Arduino) was used for collecting and processing IMU data for attitude estimation. This ECU is based on the Atmel SAM3X8E ARM Cortex-M3 CPU. The 32-bit ARM core is fast enough for communicating with the IMU, to realize the sensor fusion algorithm and outputting results of the attitude measurement data to peripheral equipment by serial port. Figure 1 shows an application of the attitude measurement unit communicating with a computer.

In the IMU, an accelerometer was used for measuring triaxial linear acceleration. Figure 2 shows the coordinates and tilt angle of the accelerometer. Coordinate $O-X Y Z$ is the geodetic

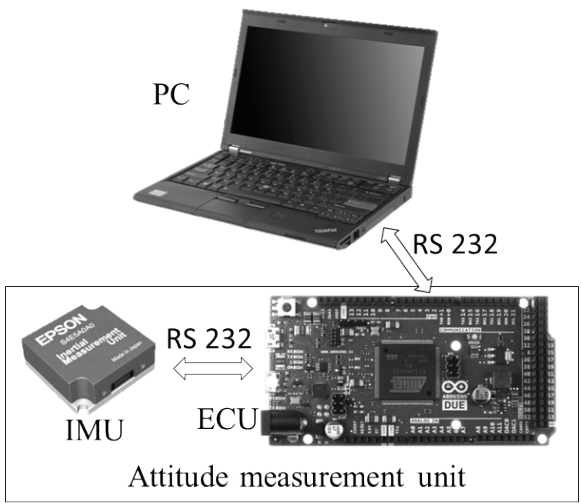

Figure 1- Schematic diagram of the attitude measurement unit

coordinate system, and coordinate $o-x y z$ is the IMU body-fixed coordinate system. The tilt angle between the $O X$ axis and $o x$ axis is called pitch, and the tilt angle between the $O Y$ axis and $o y$ axis is called roll. As is well known, in nature, the acceleration of gravity vector is directed to the center of the earth. The value measured by an accelerometer is the projection addition of acceleration of gravity and absolute acceleration (Chen et al 1994). Thus, when the IMU remains steady and Corioli's acceleration and noise can be ignored, the relationship among the components of acceleration of gravity can be described as shown in Equation (1).

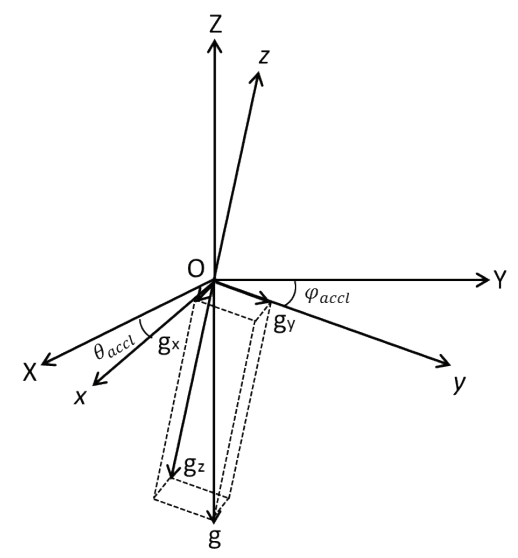

Figure 2- Attitude angle of the accelerometer in coordinate 
$g=\sqrt{g_{x}^{2}+g_{y}^{2}+g_{z}^{2}}$

Where; $g$, acceleration of gravity; $g_{x}, g_{y}$ and $g_{z}$, acceleration components of gravity in the $o x, o y$ and $o z$ axes, respectively.

Based on trigonometric functions, the formulas of attitude angle can be obtained by Equation (2) and Equation (3).

$$
\begin{gathered}
\theta_{a c c l}=-\arcsin \left(\frac{g_{x}}{g}\right) \\
\varphi_{a c c l}=\arctan \left(\frac{g_{y}}{g_{z}}\right)
\end{gathered}
$$

Where; $\theta_{a c c l}$ and $\varphi_{\text {accl }}$, denote the pitch and roll angles, respectively.

However, the angle between the $O Z$ axis and $o z$ axis, denoted as yaw, is in the horizontal plane. The angle is orthogonal to the acceleration of gravity. Thus, projection on the horizontal plane cannot be obtained, and therefore the yaw cannot be calculated from the accelerometer. In addition, the environment in which the agricultural robot works is complex. There will be a random noise in measurements by the accelerometer when there is strenuous accelerated motion.

The gyroscope can measure the angular rate of the IMU. The triaxial angles $\Phi_{g y r o}$ can therefore be obtained by angular rate via an integral as shown in Equation (4).

$\Phi_{\text {gyro }}=\int \omega_{\text {gyro }} \mathrm{dt}$

Where; $\omega_{\text {gyro }}$ is the measured angular rate; $d t$ is the gyroscope measurement sampling period.

Because of the temperature variation, unstable moment of force and noise jamming denoted by $\sigma$, the gyroscope will accumulate drift error that will become larger with time, as can be seen in Equation (5). $\Phi_{g y r o}=\int\left(\omega_{\text {gyro }}+\sigma\right) d t$

Thus, attitude can be measured by using only an accelerometer or a gyroscope, but each sensor has the measurement limitation. The accelerometer has a motion bandwidth problem, and the gyroscope has angle drift error when operation time is long.

\subsection{Sensor fusion method}

To avoid the measurement limitations by using only an accelerometer or a gyroscope, the sensor fusion method was used to integrate data from the accelerometer and the gyroscope. Figure 3 shows a block diagram of the sensor fusion methods. In this study, two methods were discussed and compared. One is a self-adaptive complementary filter and the other one is a Kalman filter.

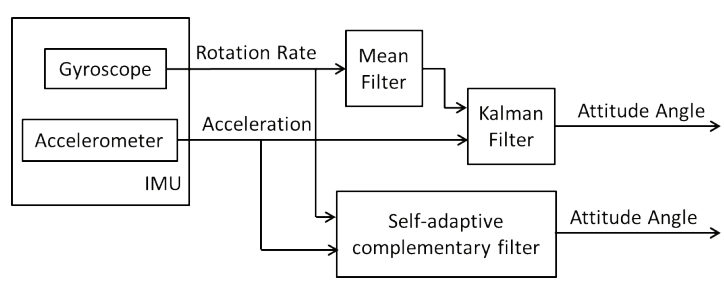

Figure 3- Block diagram of the sensor fusion methods

Because of the high-pass characteristics of gyroscope and low-pass characteristics of accelerometer, the complementary filter can combine the advantages from the both sensors. A student group which was sponsored by Edgerton center at MIT (Colton 2007) described the complementary filter as Equation (6).

$\operatorname{angle}_{i+1}=(1-k) \cdot\left(\operatorname{angle}_{i}+\omega_{g r y o} \cdot d t\right)+k \cdot$ angle $_{\text {acc }}$

Where; $k$, filter weight coefficient; angle $e_{a c c}$, angle calculated by accelerometer.

In order to make the complementary filter work better, the choice of is important. When is small, the estimation result depends on the angular rate, the influence from accumulate drift error is big. When is big, the estimation result depends on acceleration, the influence from accelerated motion is big. Therefore, based on the state of motion, a self-adaptive complementary filter was designed as Equation (7). The determination of $k_{i}$ was based on Equation (8).

$$
\begin{aligned}
& \text { angle }_{i+1}=\left(1-k_{i}\right) \cdot\left(\text { angle }_{i}+\omega_{g y y} \cdot d t\right)+k_{i} \cdot \text { angle }_{a c c} \\
& k_{i}=\left\{\begin{array}{cc}
0, & \text { when }\left|a_{i}-g\right|>\lambda \\
k_{\max } & \text { when }\left|a_{i}-g\right|<\lambda \\
p \cdot\left|a_{i}-g\right|+q & \text { when } \lambda<\left|a_{i}-g\right|<\lambda
\end{array}\right.
\end{aligned}
$$


Where; g, acceleration of gravity; $a_{i}$, resultant acceleration; parameters $\lambda$ and $\lambda$ are based on environment noise and motion state; $p$ and $q$, determined by the parameters $\lambda, \lambda$ and the extremum of weight coefficient $k_{\max }$.

The Kalman filter (Kalman 1960) is another popular filter which is used on data fusion processing. In order to prevent the high frequency measured noise on the gyroscope, the mean filter is used to eliminate the outlier signal as a pre-process of the angular rate obtained by the gyroscope in this low-cost IMU. The mean filter is expressed in Equation (9).

$\omega_{\text {gyro }}=\frac{\sum_{\mathrm{t}=1}^{\mathrm{n}} \omega_{\mathrm{t}}}{\mathrm{n}}$

Where; $n$, window size of the mean filter. In consideration of the ECU computing scale and time delay, $n=3$ was used in this study.

The Kalman filter is optimal when process noise and measurement noise can be modelled by white Gaussian noise (St-Pierre \& Gingras 2004). As mentioned above, the relationship between attitude angle and angular rate is derivative relation. The system can therefore be described as a discrete-time state equation expressed in Equation (10).

$$
X(k \mid k-1)=A \cdot X(k-1 \mid k-1)+B \cdot U(k)
$$

Where; $A$, system transition matrix $A=\left[\begin{array}{cc}1 & -T s \\ 0 & 1\end{array}\right]$; $B$, system control matrix $B=\left[\begin{array}{c}T s \\ 0\end{array}\right] ; T_{s}$, sampling period; $X(k \mid k-1)$, system state in moment $k$ estimated by state $k-1 ; U(k)$, exogenous state control input in moment $k(U(k)=0$ in this study). The covariance of $X(k \mid k-1)$ is shown in Equation (11).

$$
P(k \mid k-1)=A \cdot P(k-1 \mid k-1) \cdot A^{T}+Q
$$

Where; Q, covariance matrix of the system process noise $Q=\left[\begin{array}{cc}q_{-} a c c l & 0 \\ 0 & q_{-} \text {gyro }\end{array}\right]$, in which $q_{-}$accl is the noise covariance of the accelerometer; $q$ gyro, noise covariance of the gyroscope; matrix $A^{T}$, transpose of matrix $A$.

The optimal estimation $X(k \mid k)$ in state $k$ is calculated by Equation (12).

$X(k \mid k)=X(k \mid k-1)+k_{g}(k) \cdot(Z(k)-H \cdot X(k \mid k-1))$

Where; $H$, observation matrix, $H=\left[\begin{array}{ll}1 & 0\end{array}\right] ; k_{g}(k)$, Kalman gain which is updated by Equation (13).

$k_{g}(k)=\frac{P(k \mid k-1) \cdot H^{T}}{H \cdot P(k \mid k-1) \cdot H^{T}+R}$

Where; $R$ is a covariance matrix of error in measurement by the accelerometer. In order to update the Kalman filter, the covariance equation is updated by Equation (14).

$$
P(k \mid k)=\left(I-k_{g}(k) \cdot H\right) \cdot P(k \mid k-1)
$$

Where; $I$, unit matrix, $I=\left[\begin{array}{l}1 \\ 1\end{array}\right]$.

Based on recursive functions from Equation (7) to Equation (11), it is possible to calculate iteratively to find the optimal estimate attitude angle.

\section{Results and Discussion}

In order to verify the validity of the sensor fusion methods that combines the accelerometer and gyroscope, which are better than using each sensor alone, two indexes of the sensors were chosen to evaluate performance. One was the drift error and the other was the dynamic attitude angle. According to the electrical specifications of the IMU, the initial parameters of the Kalman filter

\begin{tabular}{|c|c|c|c|c|c|c|c|c|}
\hline & \multicolumn{5}{|c|}{ Kalman filter } & \multicolumn{3}{|c|}{ Complementary filter } \\
\hline Parameter & $T S$ & & $A$ & 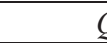 & & $\lambda$ & $\lambda$ & $k_{\max }$ \\
\hline Value & $\begin{array}{c}0.008 \\
\mathrm{~s}\end{array}$ & {$\left[\begin{array}{l}1 \\
0\end{array}\right.$} & $\left.\begin{array}{c}-0.008 \\
1\end{array}\right]$ & {$\left[\begin{array}{c}0.001 \\
0\end{array}\right.$} & $\left.\begin{array}{c}0 \\
0.003\end{array}\right]$ & $0.2 \mathrm{G}$ & $0.004 \mathrm{G}$ & 0.2 \\
\hline Parameter & $R$ & & $X_{0}$ & $P$ & & $p$ & $q$ & \\
\hline Value & {$[0.03]$} & & {$\left[\begin{array}{l}0 \\
0\end{array}\right]$} & {$\left[\begin{array}{l}0.04 \\
0.04\end{array}\right.$} & $\left.\begin{array}{l}0.04 \\
0.04\end{array}\right]$ & -0.918 & 0.204 & \\
\hline
\end{tabular}
and complementary filter are shown in Table 2.

Table 2- Initial parameters of the Kalman filter and complementary filter 


\subsection{Filters comparison}

Drift error is directly related to measurement accuracy and stability of the measurement system. In this study, we kept the IMU static in a horizontal plane and then compared the performances using the gyroscope alone, the accelerometer alone and two sensor fusion methods. Figure 4 shows a comparison of results for drift during a period of 10 minutes. Figure 4(a) shows drift in the roll direction, and Figure 4(b) shows drift in the pitch direction. In this coordinate system, the abscissa is the sampling time in seconds. The ordinate is drift angle in degrees. Because of error accumulation, drift measured by gyroscope alone continuously increases to -14.6 degrees in the roll direction and to 19.1 degrees in the pitch direction. Drift measured by the accelerometer alone does not increase with time, but data oscillate in a wide range area in both roll and pitch directions. When the self-adaptive complementary filter and Kalman filter were used, drift was almost zero and was smoother than the data from the accelerometer.

The dynamic characteristic is therefore a very important index to evaluate the attitude measurement unit. Similar to the above evaluation steps of drift error, the dynamic attitude angle data was logged when rotating the attitude measurement unit in different rotation directions. Figure 5 shows a comparison of results for dynamic attitude angles when using the gyroscope alone, the accelerometer alone and two sensor fusion methods. In this coordinate system, the abscissa is the sampling time in seconds. The ordinate is the dynamic attitude estimated angle in degrees. Because the IMU worked in a random variable motion,

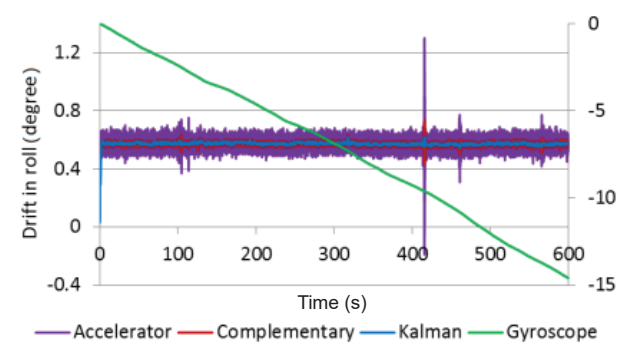

(a) Drift in roll direction

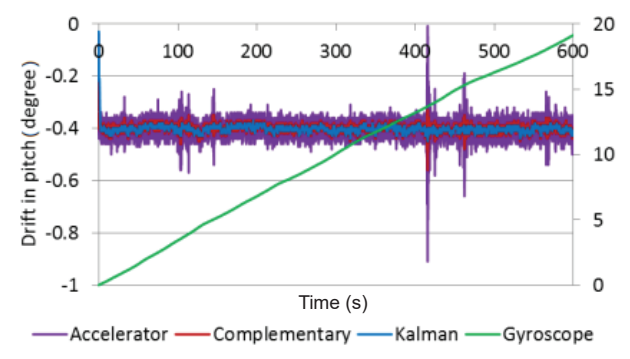

(b) Drift in pitch direction

Figure 4- Comparison for drift when using the gyroscope alone, accelerometer alone and two sensor fusion methods

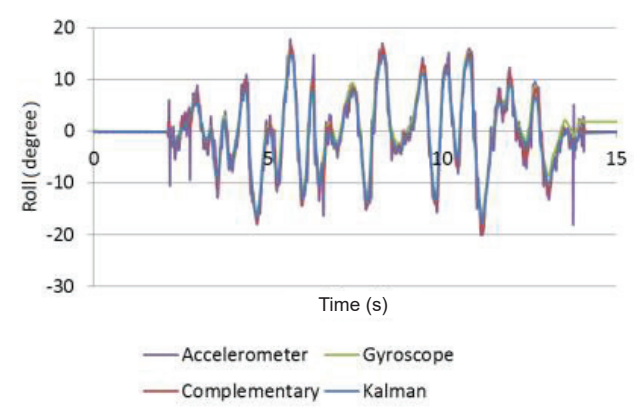

(a) Dynamic attitude in roll direction

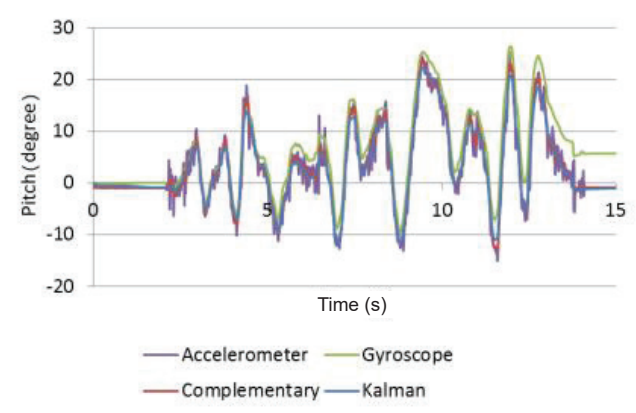

(b) Dynamic attitude in pitch direction

Figure 5- Comparison for dynamic attitude angles when using the gyroscope alone, the accelerometer alone and two sensor fusion methods 
we can see that the dynamic curve measured by the accelerometer is not stable, a lot of spurious signal errors superpose on the dynamic curve, especially at the position where motion direction is changed. In a short time, the data drift obtained by the gyroscope alone is not very obvious. However, at the end of the sampling time, the attitude angle cannot return to the original value. The drift errors are 1.8 degrees in the roll direction and 5.7 degrees in the pitch direction. Otherwise, the dynamic curve which was estimated by the self-adaptive complementary filter was better than the performance of each sensor alone. A large numbers of spurious signals were removed, but some parts of wide oscillations still exist, especially on the data wave crest. On the other hand, the dynamic curve estimated by Kalman filter is much more robust and smooth.

\subsection{System performance comparison}

Through the above comparative analysis, it was found that the Kalman filter processing was superior to the single sensor measurement and the complementary filter. For in-depth discussion, we compared the developed small-sized and low-cost attitude measurement unit based on Kalman filter processing with a highly precise aviation-level FOG attitude measurement equipment (JCS7401A, Japan Aviation Electronics Industry), which can output attitude angles directly with accuracy of \pm 0.2 degrees and digital measured resolution of 0.1 degrees.

At first, the attitude measurement unit and the FOG were fixed together on the same plane and drift data were logged. Figure 6 shows a comparison of results for drift in the roll and pitch direction during a period of 10 minutes. The drift data show that the performance of the attitude measurement unit is very close to that of the precise FOG. The drift data of the two devices are both stable in the range of 0.1 degrees. That is to say the developed attitude measurement unit can inhibit the angle drift for providing high static stability.

As shown by results presented in Figure 6, data obtained by the sensor fusion method not only inherits the little drift characteristics from the accelerometer but also inherits the transient

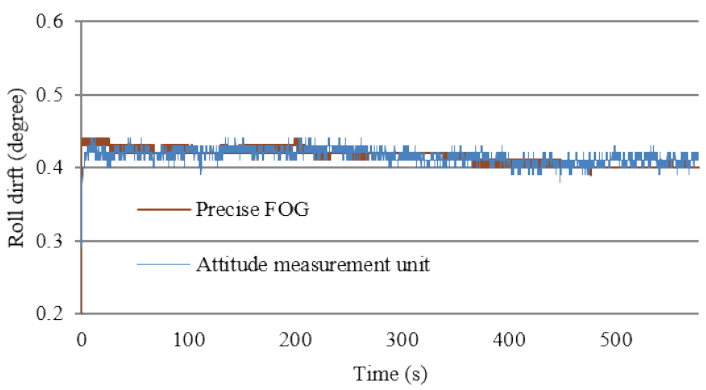

(a) Drift in roll direction

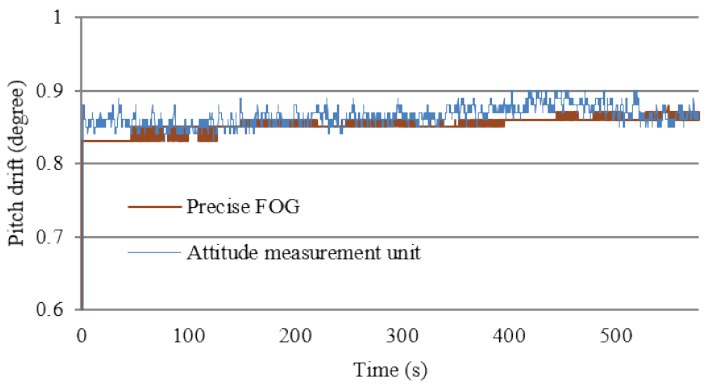

(b) Drift in pitch direction

Figure 6- Comparison for drift when using the developed attitude measurement unit and precise FOG

stability from the gyroscope. Now, we compared the dynamic attitude angle obtained from both the attitude measurement unit using the Kalman filter and the highly precise FOG. In order to ensure high accuracy of comparison as far as possible, the attitude measurement unit and FOG were fixed together and in the same coordinate. The set-up situation is shown in Figure 7.

As it was done when comparing the dynamic angles measured by the gyroscope alone, the accelerometer alone and the two sensors fusion methods, we randomly rotated the attitude measurement unit and the FOG synchronously in different rotation directions and logged the data. Figure 8 shows that the measurement of dynamic attitude angle by the attitude measurement unit coincides well with that by the highly precise FOG. Based on statistics, the RMS errors are 0.3 degrees in the roll direction and 0.4 degrees in the pitch 


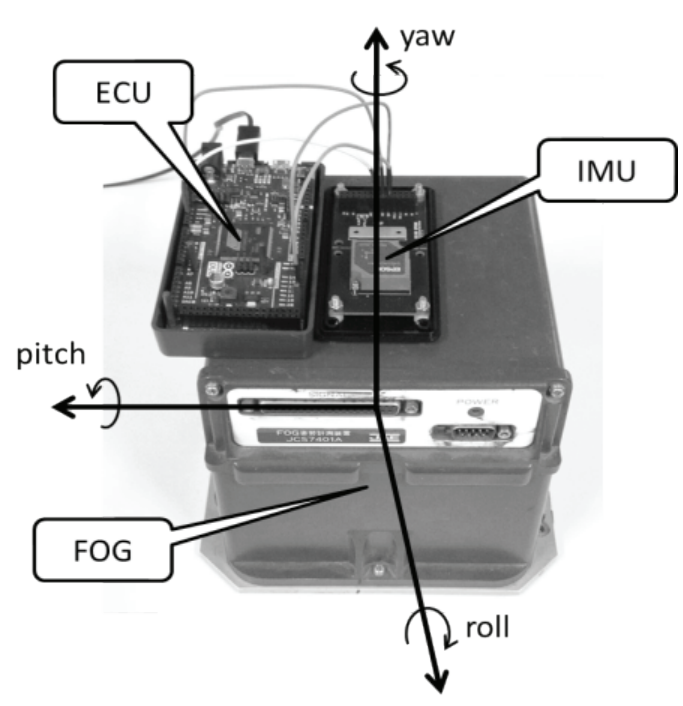

Figure 7- Fixation situation of the attitude measurement unit and FOG

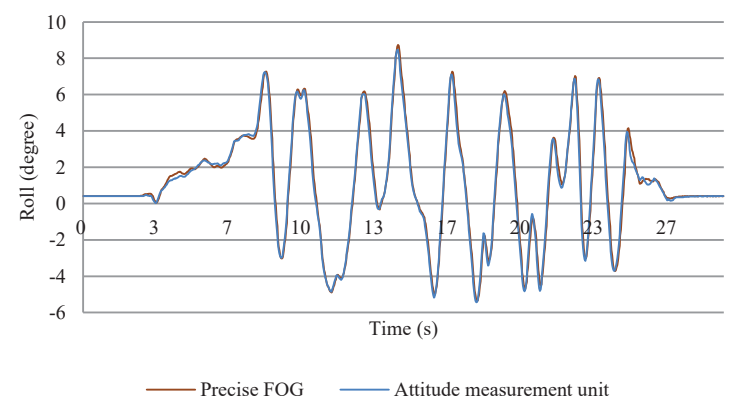

(a) Dynamic attitude in roll direction

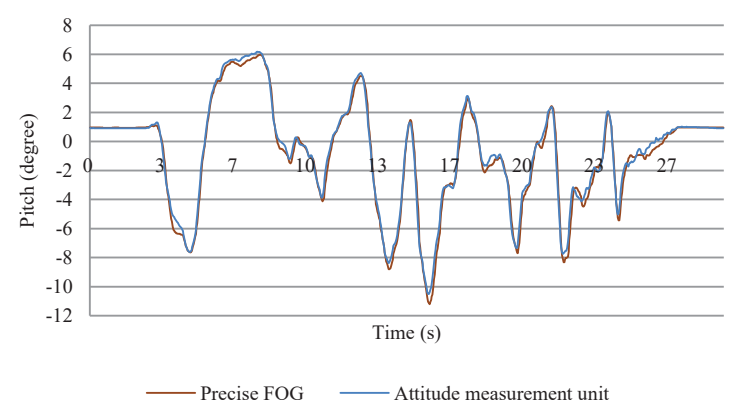

(b) Dynamic attitude in pitch direction

Figure 8- Comparison for dynamic attitude angle when using the attitude measurement unit and the precise FOG direction. Several errors which are bigger than 1 degree appeared once in a while. The maximum error in the roll direction is -1.3 degrees and the maximum error in the pitch direction is 1.4 degrees.

As we know, the farming conditions are complex for agricultural machinery such as the level and smooth of field surface, temperature, humidity and so on. Experiment is the sole criterion for testing the developed attitude measurement unit. A developed robot combine harvester (Zhang et al 2013) was utilized to attach the attitude measurement unit and precise FOG. The experiment was executed in the farm of Hokkaido University. This robot combine harvester could run autonomously under a predetermined map. The developed attitude measurement unit and the high precise FOG recorded the attitude of the robot respectively. The tests were conducted in different running speeds of robot of $0.5,0.7$ and $1.0 \mathrm{~ms}^{-1}$. Figure 9 shows the

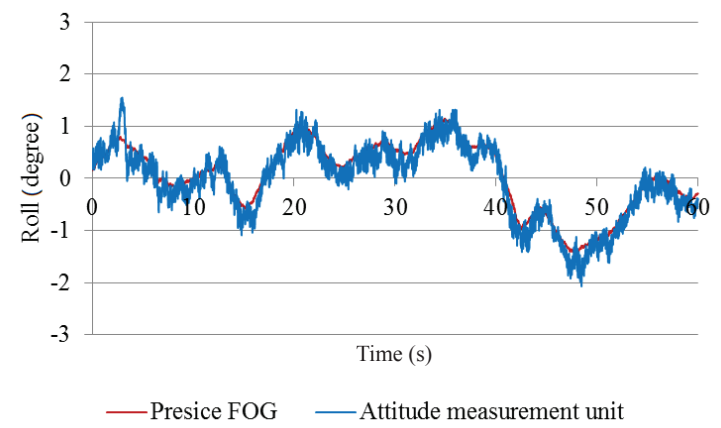

(a) Farm test in roll direction

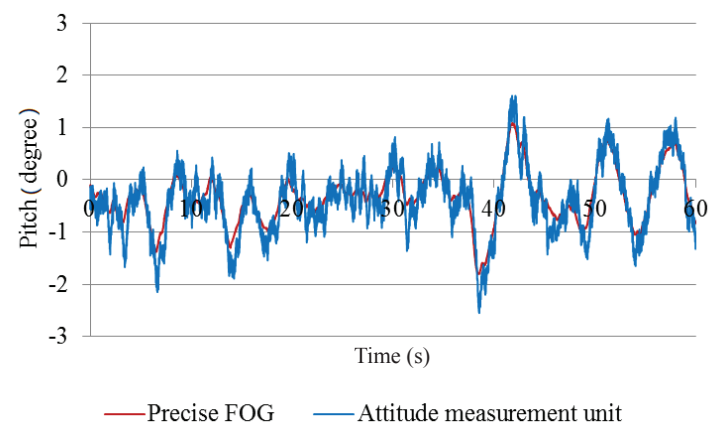

(b) Farm test in pitch direction

Figure 9- Comparison for farm test when using the attitude measurement unit and the precise FOG 
record result of robot attitude when robot run in speed of $0.7 \mathrm{~ms}^{-1}$. The dynamic behaviour of attitude measurement unit is close to the precise FOG. The RMS errors are 0.2 degrees in the roll direction and 0.3 degrees in the pitch direction. However, the measurement noise of the attitude measurement unit is obvious in the sub-degree level which is not good as the FOG. The noise of ripple wave on the attitude angle was brought from the engine vibration. The similar phenomenon also appeared in the tests of speed of 0.5 and $1.0 \mathrm{~m} \mathrm{~s}^{-1}$. Table 3 summarizes the errors of the attitude measurement unit compared to the precise FOG in different robot running speed. That means the developed attitude measurement unit need to be improved much more on the inhibition of high-frequency noise.

Table 3- Errors of dynamic attitude angle in different robot running speeds

\begin{tabular}{ccccccc}
\hline \multirow{2}{*}{$\begin{array}{c}\text { Speed } \\
\left(\mathrm{m} \mathrm{s}^{-1}\right)\end{array}$} & \multicolumn{5}{c}{ Roll } \\
\cline { 2 - 7 } & Max & RMS & Mean & Max & RMS & Mean \\
\hline 0.5 & 0.4 & 0.1 & -0.1 & 0.6 & 0.2 & -0.1 \\
0.7 & 0.8 & 0.2 & 0.1 & 1.0 & 0.3 & 0.1 \\
1.0 & 0.6 & 0.2 & -0.1 & 1.3 & 0.3 & -0.1 \\
\hline
\end{tabular}

\section{Conclusions}

In this study, a small-sized and low-cost electronic unit was developed to provide attitude estimation with acceptable accuracy for light-loaded, small-sized and low-priced agricultural robot applications. This attitude measurement unit was composed of a small, low-cost IMU and an ECU by using sensor fusion methods. Based on the characteristic of gyroscope and accelerator, a self-adaptive complementary filter and a Kalman filter were discussed and compared. According to the comprehensive evaluation of drift error and dynamic motion, the Kalman filter is better to compensate the IMU drift, improved noise immunity and reduced measurement error. In the comparison with a highly precise FOG, the drift of attitude measurement unit approximates to the performance of the FOG. Finally, the results of farm test in dynamic characteristic shows that the performance of attitude measurement unit is close to the precise FOG, but the noise of ripple wave on the attitude angle exist. This issue needs to be solved in the future research. In a word, this developed attitude measurement unit can be applied to the low-cost small-sized harvesting robot arm, the greenhouse robots and agriculture drones.

\section{References}

Chen J, Lee S \& Debra D B (1994). Gyroscope free strapdown inertial measurement unit by six linear accelerometers. Journal of Guidance, Control and Dynamics 17(2): 286-290

Colton S (2007). The balance filter. Retrieved in May, 15, 2016 from http://web.mit.edu/first/segway/\#how

Inoue K, Nii K \& Zhang Y (2009). Tractor guidance system for farm work using DGPS and gyroscope. Journal of Robotics and Mechatronics 21(3): 394-402

Kalman R E (1960). A new approach to linear filtering and prediction problems. Transactions of the ASMEJournal of Basic Engineering 82(Series D): 35-45

Kise M, Noguchi N, Ishii K \& Terao H (2001). Development of agricultural autonomous tractor with an RTK-GPS and a FOG. Proceedings of the $4^{\text {th }}$ IFAC Symposium on Intelligent Autonomous Vehicles, 5-7 September, Sapporo, pp. 103-108

Noguchi N, Reid J F, Zhang Q, Will J D \& Ishii K (2001). Development of robot tractor based on RTK-GPS and gyroscope. ASAE Annual Meeting, 29 July-1 August, Sacramento, Paper No: 011195

Robinson L (2012). Think smart and small for the future of crop protection. Retrieved in May, 10, 2016 from http://www.fwi.co.uk/articles/26/06/2012/133520/ think-smart-and-small-for-the-future-of-cropprotection.htm

St-Pierre M \& Gingras D (2004). Comparison between the unscented Kalman filter and the extended Kalman filter for the position estimation module of an integrated navigation information system. 2004 IEEE Intelligent Vehicles Symposium, 14-17 June, Parma, pp. 831-835

Zhang Z, Noguchi N, Ishii K, Yang L \& Zhang C (2013). Development of a robot combine harvester for wheat and paddy harvesting. $5^{\text {th }}$ IFAC Conference on BioRobotics, 27-29 March, Sakai, Japan, pp. 45-48 